\title{
Measurement Scheme and Automatic Prediction for Ground Vibration Induced by High-Speed Rail on Embankments
}

\author{
Yit-Jin Chen $^{a^{*}}$, Yi-Jiun Shen ${ }^{\mathrm{b}}$ and Chi-Jim Chen ${ }^{\mathrm{c}}$ \\ $a^{a^{*}}$ Department of Civil Engineering, Chung Yuan Christian University, Chung-Li, Taiwan \\ ${ }^{b}$ CECI Engineering Consultants, Inc., Taiwan, No. 323, Yangguang St., Neihu District, Taipei, Taiwan \\ ${ }^{c}$ Department of Computer Science and Engineering, National Taiwan Ocean University, Keelung, Taiwan \\ E-mail: yjc@cycu.edu.tw, yjs@ceci.com.tw, nyy86@yahoo.com.tw
}

\begin{abstract}
-
Experience shows that ground vibration induced by high-speed trains can reach levels that cause environmental problems, such as human annoyance, possible damage to old and historical buildings, and interruption of sensitive instrumentation and processes. In engineering, understanding the characteristics of the vibration source, path, and influence distance on various influence factors is essential. Thus, a reliable vibration measurement scheme for highly sensitive vibration areas is proposed to acquire the characteristics of ground vibration induced by passing trains. From a wide variety of field measurements and monitoring using vibration sensors, the main characteristics that affect overall vibration levels include train speed, ground condition, measurement distance, and supported structure. Based on the database of measurement results, the most widely used kernel learning algorithm, support vector machine (SVM) algorithm, is adopted in this research to predict the vibration levels induced by high-speed trains on embankments. Analysis results show that the developed SVM model can predict vibration levels with an accuracy rate of $\mathbf{7 0 \% - 8 5 \%}$ for four types of vibration levels, namely, overall, low, middle, and high frequency ranges. The methodology for developing an automatic prediction system for ground vibration levels induced by highspeed trains is also described in this paper.
\end{abstract}

Keywords -

Environmental Vibration; Ground Vibration Measurement; High Speed Rail; Embankment; Ground Vibration Prediction; Support Vector Machine

\section{Introduction}

Many countries plan to build high-speed rail (HSR) systems because they enable train services to be faster and more convenient than motorcars and aircrafts. The HSR system has proven to be effective at bridging the gap between vast geographic distances in a relatively short time span, and the benefits of HSR system go beyond travel and eco-friendliness [1].

However, experience also shows that the ground or building vibration induced by train systems can reach levels that cause human annoyance, possible damage to old and historical buildings, and interruption of sensitive instrumentation and processes. Therefore, a reliable vibration measurement scheme is essential to obtain the key characteristics of ground vibration induced by passing trains. Moreover, the development of an automatic ground vibration prediction system is needed, especially in high vibration-sensitive areas.

Among all the possible influence factors for nearfield and far-field vibrations, numerous authors [2-6] have concluded that train speed, ground condition, and frequency dependence are the most important factors in evaluating the vibration behavior of high-speed trains. Chen et al. [5] measured the ground vibration induced by Taiwan high-speed trains on embankments with a wide variety of influence factors, including train speed, ground condition, and embankment height. The study included near-field vibration characteristics and far-field vibration propagation. However, a convenient assessment model is also useful for engineers to predict possible vibration effects in the preliminary design stage. Therefore, systematically understanding ground vibration characteristics and establishing a simple vibration assessment for high-speed trains on embankments are important.

In this study, a reliable vibration measurement scheme for highly sensitive vibration areas is proposed. Extensive measurement data from Taiwan high-speed trains on embankments are used to establish ground vibration characteristics. A simple and widely used prediction model [7, 8], the support vector machine (SVM) technique, is then established based on these characteristics as a preliminary ground vibration assessment. Both measured and predicted vibration levels are compared to verify the reliability of the prediction model. The methodology of developing an automatic prediction system for ground vibration levels induced by high-speed trains on embankments is provided. 


\section{Vibration Measurement Scheme}

To perform train-induced ground vibration measurements, some issues must be considered when planning the vibration measurement scheme. They include in-situ conditions and trainset. By understanding the characteristics of these issues, a vibration measurement scheme and data analysis methods are proposed for highly sensitive vibration areas. A background of the important issues, measurement scheme, and analysis methods are briefly summarized in the following sections.

\subsection{Important Issues in Train-induced Ground Vibration Measurement}

\subsubsection{Weather and Site Conditions}

Weather conditions may affect vibration measurement results. Weather conditions include air pressure, relative humidity, wind speed, wind direction, rainfall, temperature, and earthquakes [9]. These conditions must be recorded properly when vibration measurement results are evaluated. The qualities and uncertainties of the vibration measurements are closely related to weather conditions. The instruments for vibration measurements must be specified according to weather conditions.

The selection of measurement sites is another critical issue. Free-field measurement sites can be selected with careful consideration to minimize interaction effects. Localized effects on the measurements of man-made features of the particular location should also be minimized. Therefore, sites cannot be on localized topographic features, such as hills, ridges, or valleys, which may create unexpected ground vibrations. Sites should also not be in or on locally anomalous soft soils. Moreover, selected sites should be kept away from potential sources of vibration, such as large motors, large pipelines, large masts, heavy vehicle traffic, and industrial activities.

\subsubsection{Train Operation Condition}

Train speeds are known to affect the time history and frequency content of the free-field vibration response at various distances from track center. Thus, information on train operation conditions must be obtained when measuring train-induced ground vibration. This information includes train speed and the time when the train passes by certain marked targets. Photoelectric sensors mounted on the parapet of bridges can be used to obtain train speeds and the time a train passes. The signal is "on" during the passage of a train, and the signal is "off" before and after the train passes, as shown in Figure 1. Train speed can be calculated by obtaining the length of the train or distance between two photoelectric sets. The time that a train passes the photoelectric sensor can be obtained using the time history of the signal records. Given that ground vibration measurements have many uncertainties, measuring several passages per train category is recommended.

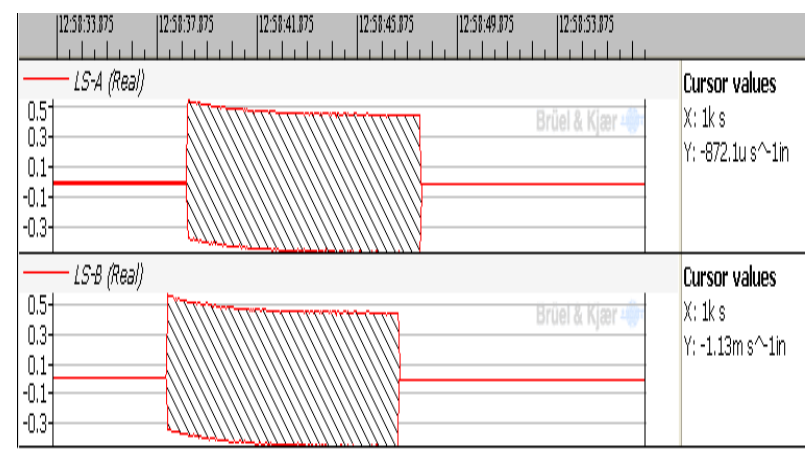

Figure 1. The signal during the passage of a train (LS-A and LS-B are two sets of photoelectric sensors with the distances of $25 \mathrm{~m}$ )

\subsection{Trainset}

The trainset of the Taiwan high-speed trains consists of 12 train cars with 10 cars for passengers and two cars as locomotives. The lengths of the passenger car and motive car are 25 and $27 \mathrm{~m}$, respectively; thus, the total length of the trainset is $304 \mathrm{~m}$. The trainset configuration and related dimensions of Taiwan high speed rail (THSR) are shown in Figure 2.

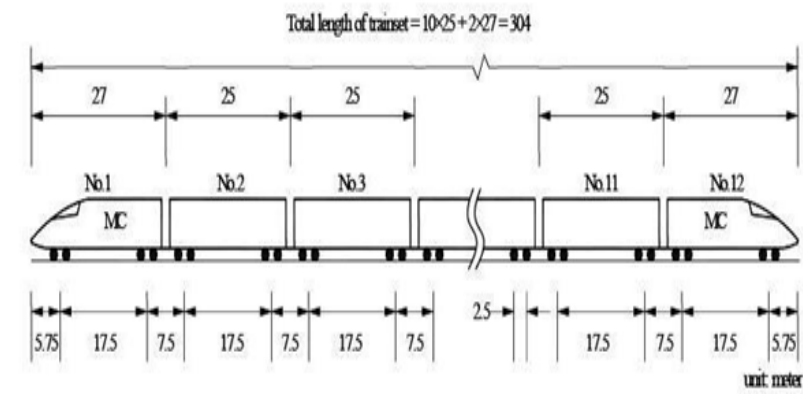

Figure 2. Configuration of trainset for Taiwan high-speed trains

\subsection{Measurement of Ground Vibration}

The ISO 804118 requirements are the main reference for installing measuring equipment and selecting measurement points. Basic measuring equipment, such as accelerometers, integrator, and a data acquisition system, is used for this study. The following procedure is used for installing sensors that attach to the ground: 
(1) A pit with proper dimensions in which accelerometers can be installed is excavated.

(2) The standard sand is placed on the bottom of the pit to even the excavated surface.

(3) The excavated surface is compacted, and the surface is assured in the horizontal level.

(4) Three- dimensional accelerometers that connect to a steel plate as a firm base are placed on the ground.

(5) The accelerometer direction is set as follows: the $\mathrm{X}$-direction is the direction in which the train moves; the Y-direction is perpendicular to the direction in which the train moves; and the $\mathrm{Z}$ direction is for the direction of gravity.

A set of measuring instruments and equipment is shown in Figure 3. The measured vibration accelerations include $\mathrm{X}$ (longitudinal), Y (transverse), and $\mathrm{Z}$ (vertical) directions. Only the vertical component ( $Z$ direction) is used in the subsequent discussion because some codes and studies [4-6, 10, 11] suggested the $\mathrm{Z}$ direction for analysis to simplify the process of vibration impact assessment in general situations.

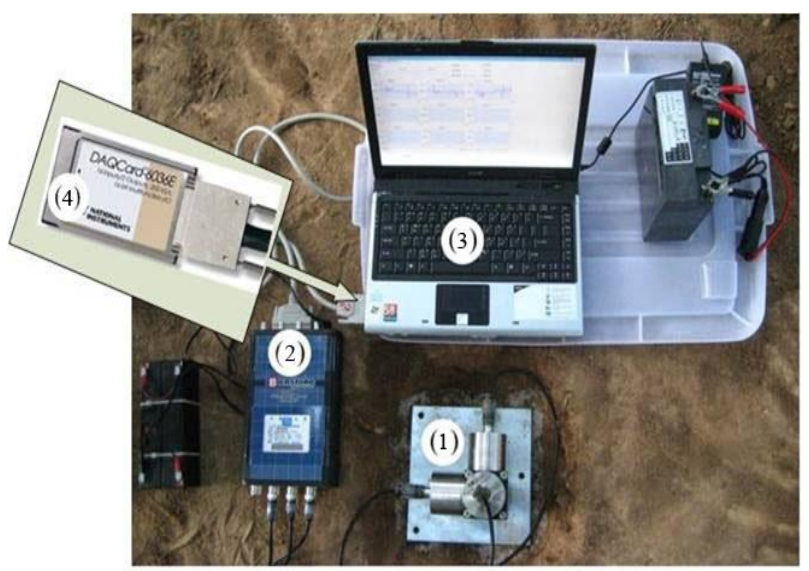

Figure 3. Measuring equipment including (1) accelerometers, (2) integrator, (3) and (4) data acquisition system

Adjacent environmental conditions are also essential to avoid any possible interruption during measurement, and ensure that all analysis data are of good quality. Microphones and digital video recorders are installed as auxiliary instruments to record noise and any activity, and such information can be used to evaluate whether other vibration sources interfere with the measurement.

The vibration measurement plan includes near-field and far-field measurements. To establish the near-field vibration database in a consistent reference plane, the distance of the near-field vibration was set at approximately $25 \mathrm{~m}$ from the track center. For far-field measurement, four to five measurement points in each site, which were in a straight line and perpendicular to the train alignment, were used to simultaneously measure ground vibration when trains passed through the specific location. The first measurement point (the nearest point from the HSR alignment) was located approximately $25 \mathrm{~m}$ from the track center, whereas the distance of the last measurement point (the farthest point from the alignment) was $200 \mathrm{~m}$ or so, which was dependent on field conditions. The remaining points were located at average intervals. Figure 4 presents the typical schematic layout of the measurement site. Before measuring, all equipment was synchronized.
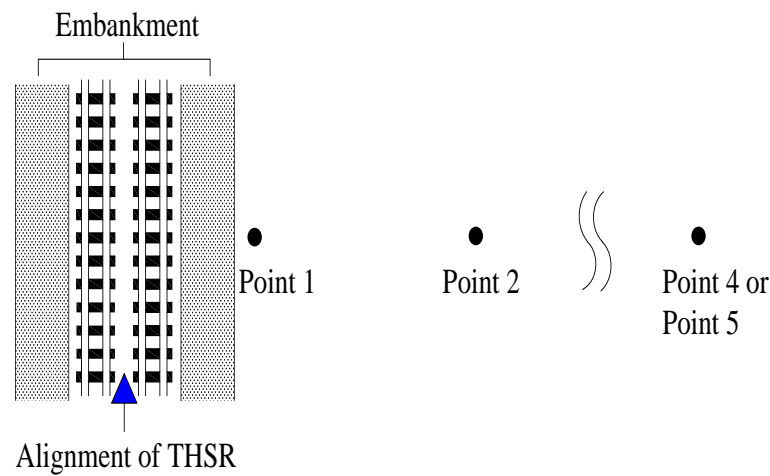

Figure 4. Typical schematic layout of measuring site

\subsection{Data Analysis Method}

Based on the characteristics of ground vibration induced by high-speed trains, a range of amplitudes (10-100 dB ref. 1 micro-inch/sec) and frequencies (1$100 \mathrm{~Hz}$ ) is needed for the assessment. To evaluate the frequency effect, the frequency domain of a one-third octave band for the center frequency range of $1-100 \mathrm{~Hz}$ is adopted to describe the velocity vibration level in decibels $(\mathrm{dB})$. The ground vibration level (VL) is expressed in terms of its root-mean-square (RMS) velocity. The RMS velocity level is computed using the following steps:

(1) Fast Fourier Transform (FFT) is used to transfer the velocity of time history, $\mathrm{y}(\mathrm{t})$, to the frequency domain. The power spectrum density function (PSDF), $S_{y}(f)$, is then calculated as follows:

$$
S_{y}(f)=\frac{2|Y(f)|^{2}}{T}
$$

where $|\mathrm{Y}(\mathrm{f})|=$ FFT amplitude, $\mathrm{T}=$ time interval of $\mathrm{y}(\mathrm{t})$, and $\mathrm{f}=$ frequency $(\mathrm{Hz})$. The suitable time interval $(8 \mathrm{~s}$ in this study), which covers ground excitation during the passage of the train, is selected from the time history record.

(2) PSDF is accumulated from the lower band to the upper band:

$$
E_{y}\left(f_{c}\right)=\int_{f_{l}}^{f_{u}} S_{y}(f) d f
$$


where $f_{l}, f_{u}$, and $f_{c}$ are the lower band, upper band, and center frequencies, respectively. $E_{y}\left(f_{c}\right)$ represents the energy summation from $f_{l}$ to $f_{u}$. The frequencies of $f_{l}, f_{u}$, and $f_{c}$ are based on the definition of the one-third octave band in ANSI [12].

(3) The RMS of $\sigma_{\mathrm{y}}\left(f_{c}\right)$ is calculated:

$$
\sigma_{\mathrm{y}}\left(f_{c}\right)=\sqrt{E_{y}\left(f_{c}\right)}
$$

(4) The RMS velocity level (VL), which is represented by $\mathrm{dB}$, is calculated:

$$
\mathrm{VL}(\text { in } \mathrm{dB})=20 \log _{10} \frac{\sigma_{y}\left(f_{c}\right)}{\sigma_{0}}
$$

where the referred velocity in this study is $\sigma_{0}=10^{-6} \mathrm{in} / \mathrm{s}$ $\left(=2.54 \times 10^{-8} \mathrm{~m} / \mathrm{s}\right)$.

Furthermore, the overall vibration level of one-third octave bands is used to evaluate the total vibration energy [1-9]. The overall vibration level can be transferred from the RMS vibration level of each onethird octave band using the following calculation:

$$
\begin{gathered}
\mathrm{VL}_{\mathrm{oa}}=10 \sum_{\mathrm{k}=1}^{\mathrm{n}} \log _{10} 10^{\mathrm{VL}(\mathrm{fk}) / 10}= \\
\sum_{\mathrm{k}=1}^{\mathrm{n}} 10 \log _{10}\left(10^{0.1 \mathrm{VL}(\mathrm{f} 1)}+10^{0.1 \mathrm{VL}(\mathrm{f} 2)}+\ldots+10^{0.1 \mathrm{VL}(\mathrm{fn})}\right)
\end{gathered}
$$

where $\mathrm{VL}_{\mathrm{OA}}=$ overall vibration level in decibels, $\mathrm{fk}=$ center frequency of each one-third octave band $(1 \ldots 100 \mathrm{~Hz}$ for the frequency of $\mathrm{f} 1 \ldots \mathrm{fn})$, and $\mathrm{VL}(\mathrm{fk})=$ vibration level for each center frequency.

\subsection{Database for Analysis}

A series of measurements was performed for this study. These measurements comprised different ground conditions, embankment heights, and train speeds. Table 1 lists the basic information for these measurements. The measurement distances $\left(D_{1}-D_{4}\right)$ were $22-203 \mathrm{~m}$ from the track center. These selected embankments have various heights ranging from $3.6 \mathrm{~m}$ to $6.8 \mathrm{~m}$.

A wide variety of ground conditions and ground shear wave velocities $\left(\mathrm{V}_{\mathrm{s}}\right)$ were considered. The ground conditions included sand/silt/clay soils (silty clay and sandy silt), gravel, and rock (sandstone). The ground conditions of these embankments ranged from soft to hard ground.

Ground shear wave velocity was used as an indicator to describe "soil stiffness." The value of $\mathrm{V}_{\mathrm{s}}$ increases with increasing soil stiffness. The National Center for Research on Earthquake Engineering (NCREE) measured the ground shear wave velocity throughout Taiwan. The site where NCREE measured the ground shear wave velocity is adjacent to the location of the ground vibration measurement in the present study. Both have relatively similar ground conditions and geotechnical parameters. The average $\mathrm{V}_{\mathrm{s}}$ ranges from $170 \mathrm{~m} / \mathrm{s}$ to $650 \mathrm{~m} / \mathrm{s}$. The values of average $V_{s}$ were obtained from the ground surface to $10 \mathrm{~m}$ deep, based on the suggestion by Yoshioka [6], because such values represent surface wave analysis. The database was considered a sufficient representative sample for evaluating ground vibration characteristics.

Table 1. Basic information of measurement sites

\begin{tabular}{|c|c|c|c|c|c|c|c|}
\hline $\begin{array}{c}\text { Site } \\
\text { No. }\end{array}$ & $\begin{array}{c}\text { Soil } \\
\text { Type }\end{array}$ & $\begin{array}{c}\text { Height } \\
(\mathrm{m})\end{array}$ & $\begin{array}{c}\mathrm{V}_{\mathrm{s}} \\
(\mathrm{m} / \mathrm{s})\end{array}$ & $\begin{array}{c}\mathrm{D}_{1} \\
(\mathrm{~m})\end{array}$ & $\begin{array}{c}\mathrm{D}_{2} \\
(\mathrm{~m})\end{array}$ & $\begin{array}{c}\mathrm{D}_{3} \\
(\mathrm{~m})\end{array}$ & $\begin{array}{c}\mathrm{D}_{4} \\
(\mathrm{~m})\end{array}$ \\
\hline 1 & $\begin{array}{c}\text { silty } \\
\text { clay }\end{array}$ & 5.3 & 170 & 28 & 53 & 78 & 101 \\
\hline 2 & $\begin{array}{c}\text { sandy } \\
\text { silt }\end{array}$ & 5.2 & 230 & 33 & 68 & 93 & 118 \\
\hline 3 & gravel & 3.6 & 430 & 34 & 69 & 149 & 203 \\
\hline 4 & $\begin{array}{c}\text { sand- } \\
\text { stone }\end{array}$ & 6.8 & 650 & 22 & 47 & 122 & 202 \\
\hline
\end{tabular}

\section{Vibration Measurement Results}

After performing FFT in Section 2.4, the measurement results are shown in Table 2. The vibration level of 21 frequencies for the one-third octave band with $1-100 \mathrm{~Hz}$ is classified based on low (1-8 Hz), middle $(10-25 \mathrm{~Hz})$, and high $(31.5-100 \mathrm{~Hz})$ frequency ranges. These frequency ranges were selected based on an observation of the numerous practical results and related literature $[2,3,13]$. The overall vibration level for each frequency range can then be computed using Eq. (5).

Based on a wide variety of field measurements and monitoring with vibration sensors, the main characteristics, which influence the vibration level, include geological condition, attenuation distance, and train speed, which are shown in Figure 5. The following section is a brief summary of Figure 5.

(1) For measurement distance of $25 \mathrm{~m}$, the near-field overall ground vibration level slightly increases with increasing train speed.

(2) The near-field overall ground vibration level decreases with increasing ground shear wave velocity. A softer ground leads to a higher nearfield vibration level.

(3) The attenuation of ground vibration is obvious as the distance from the track center increases.

\section{Prediction Method}

Given that SVM algorithm [7, 8] is probably the most widely used kernel learning algorithm, it is 
Table 2. Vibration measurement results

\begin{tabular}{|c|c|c|c|c|c|c|c|c|c|c|c|c|c|c|c|c|c|c|}
\hline \multirow{3}{*}{ Site } & \multirow{3}{*}{$\begin{array}{c}\mathrm{V}_{\mathrm{s}} \\
(\mathrm{m} / \mathrm{s})\end{array}$} & \multirow{3}{*}{$\begin{array}{l}\text { Speed } \\
(\mathrm{km} / \mathrm{h})\end{array}$} & \multicolumn{4}{|c|}{$D_{1}$} & \multicolumn{4}{|c|}{$\mathrm{D}_{2}$} & \multicolumn{4}{|c|}{$D_{3}$} & \multicolumn{4}{|c|}{$D_{4}$} \\
\hline & & & \multicolumn{4}{|c|}{ VL-Z-axis (dB) } & \multicolumn{4}{|c|}{ VL-Z-axis (dB) } & \multicolumn{4}{|c|}{ VL-Z-axis (dB) } & \multicolumn{4}{|c|}{ VL-Z-axis (dB) } \\
\hline & & & VLOA & $\mathrm{VL}_{\text {LOW }}$ & $V L_{\mathrm{MDDLE}}$ & $\mathrm{VL}_{\mathrm{HIGH}}$ & $\mathrm{VL}_{\mathrm{OA}}$ & $\begin{array}{l:l}\mathrm{VL}_{\text {LOW }} & \end{array}$ & $\mathrm{VL}_{\mathrm{MMDDE}}$ & $\mathrm{VL}_{\mathrm{HHGH}}$ & VLOA & $\mathrm{VL}_{\text {LOW }}$ & $V L_{M M D L E}$ & $\mathrm{VL}_{\mathrm{HHH}}$ & $V L_{O A}$ & $\mathrm{VL}_{\text {LOWV }}$ & $V L_{\mathrm{M} D D L E}$ & $V_{\text {HIGH }}$ \\
\hline & 170 & 150 & 65.7 & 47.9 & 51.7 & 64.5 & 49.5 & 45.4 & 44.3 & 44.4 & 50.6 & 49.7 & 40.4 & 40.2 & 52.8 & 52.0 & 43.4 & 40.6 \\
\hline & 170 & 170 & 66.6 & 459 & 48.1 & 65.6 & 56.6 & 55.9 & 43.3 & 46.2 & 55.7 & 55.4 & 40.8 & 41.0 & 52.0 & 51.5 & 39.1 & 39.3 \\
\hline & 170 & 180 & 64.8 & 459 & 48.1 & 65.6 & 49.6 & 45.8 & 44.6 & 43.8 & 50.5 & 49.5 & 41.1 & 39.8 & 52.1 & 513 & 428 & 39.3 \\
\hline & 170 & 190 & 65.0 & 44.5 & 48.6 & 66.5 & 50.5 & 47.7 & 44.4 & 44.0 & 50.0 & 49.2 & 40.1 & 38.6 & 48.7 & 47.1 & 41.8 & 38.4 \\
\hline \multirow[t]{8}{*}{1} & 170 & 200 & 65.7 & 49.7 & 50.8 & 64.8 & 53.0 & 47.3 & 47.1 & 49.8 & 51.3 & 47.4 & 45.8 & 46.4 & 51.7 & 47.3 & 47.9 & 44.9 \\
\hline & 170 & 210 & 64.8 & 47.4 & 51.8 & 64.4 & 49.9 & 46.8 & 43.3 & 44.7 & 48.8 & 47.7 & 39.9 & 38.6 & 47.9 & 46.1 & 41.6 & 38.2 \\
\hline & 170 & 290 & 65.1 & 55.7 & 46.3 & 67.7 & 54.5 & 51.7 & 45.7 & 49.8 & 56.1 & 52.9 & 51.9 & 47.3 & 55.2 & 53.0 & 48.3 & 47.9 \\
\hline & 170 & 300 & 64.8 & 49.7 & 50.8 & 64.8 & 54.0 & 51.4 & 45.6 & 49.0 & 56.1 & 52.6 & 520 & 48.3 & 55.1 & 528 & 49.2 & 47.1 \\
\hline & 170 & 300 & 65.1 & 47.4 & 51.8 & 64.4 & 52.8 & 46.8 & 46.7 & 49.9 & 50.8 & 47.2 & 45.5 & 45.3 & 51.3 & 46.9 & 47.4 & 44.9 \\
\hline & 230 & 200 & 68.7 & 53.5 & 57.2 & 68.2 & 54.9 & 51.3 & 51.9 & 43.5 & 54.0 & 51.6 & 49.1 & 43.9 & 52.9 & 52.5 & 42.4 & 35.1 \\
\hline & 230 & 280 & 68.4 & 51.1 & 62.4 & 67.0 & 62.1 & 50.6 & 61.6 & 46.7 & 59.7 & 54.9 & 57.7 & 46.2 & 57.5 & 51.8 & 56.0 & 40.0 \\
\hline & 230 & 290 & 69.8 & 54.7 & 59.1 & 69.2 & 58.8 & 51.3 & 57.1 & 50.9 & 57.1 & 53.7 & 52.3 & 50.2 & 56.5 & 55.3 & 49.6 & 41.8 \\
\hline \multirow[t]{8}{*}{2} & 230 & 290 & 69.3 & 50.4 & 62.8 & 68.1 & 62.8 & 520 & 62.3 & 47.0 & 60.2 & 5577 & 57.8 & 47.7 & 57.3 & 52.3 & 55.5 & 41.6 \\
\hline & 230 & 290 & 699 & 507 & 620 & 690 & 63.0 & 50.8 & 626 & 47.6 & 59.6 & 54.1 & 57.7 & 48.1 & 56.9 & 528 & 54.5 & 41.9 \\
\hline & 230 & 300 & 70.3 & 54.5 & 59.2 & 69.8 & 58.0 & 51.3 & 56.1 & 49.3 & 58.7 & 54.5 & 55.3 & 50.7 & 55.1 & 53.3 & 49.9 & 41.0 \\
\hline & 230 & 300 & 707 & 54.4 & 579 & 704 & 587 & 521 & 568 & 50.2 & 58.1 & 550 & 53.7 & 49.8 & 557 & 547 & 48.2 & 40.5 \\
\hline & 230 & 300 & 70.1 & 54.1 & 58.4 & 69.7 & 58.1 & 51.8 & 56.0 & 50.0 & 58.8 & 54.5 & 55.8 & 50.0 & 54.5 & 52.9 & 48.8 & 41.0 \\
\hline & 430 & 280 & 66.8 & 49.8 & 64.3 & 65.1 & 55.8 & 49.1 & 52.1 & 51.4 & 50.2 & 47.7 & 46.6 & 32.1 & 49.3 & 47.2 & 44.4 & 36.9 \\
\hline & 430 & 280 & 69.9 & 52.7 & 70.2 & 66.0 & 57.0 & 516 & 52.8 & 52.3 & 54.2 & 50.6 & 50.5 & 45.7 & 53.2 & 510 & 48.6 & 38.4 \\
\hline & 430 & 285 & 6999 & 48.2 & 663 & 69.8 & 56.1 & 47.6 & 507 & 53.6 & 49.8 & 460 & 47.1 & 36.4 & 50.2 & 463 & 47.4 & 38.5 \\
\hline \multirow[t]{10}{*}{3} & 430 & 290 & 67.5 & 50.8 & 66.6 & 63.8 & 56.5 & 49.8 & 53.6 & 50.8 & 50.5 & 48.4 & 46.2 & 32.5 & 51.3 & 48.8 & 47.1 & 38.7 \\
\hline & 430 & 290 & 65.9 & 47.5 & 64.7 & 62.7 & 55.9 & 47.4 & 53.0 & 51.2 & 48.3 & 44.7 & 45.5 & 32.8 & 49.1 & 45.4 & 45.9 & 38.9 \\
\hline & 430 & 290 & 69.4 & 48.5 & 66.2 & 68.3 & 56.1 & 47.8 & 509 & 53.5 & 49.8 & 45.2 & 47.7 & 36.6 & 50.6 & 46.2 & 48.1 & 39.0 \\
\hline & 430 & 300 & 69.8 & 52.7 & 65.5 & 69.1 & 57.2 & 52.4 & 50.6 & 53.7 & 53.5 & 51.9 & 48.1 & 36.4 & 52.4 & 50.3 & 47.7 & 38.6 \\
\hline & 430 & 300 & 67.4 & 51.2 & 66.8 & 63.0 & 57.5 & 50.6 & 55.0 & 51.2 & 50.3 & 47.5 & 46.9 & 33.1 & 50.6 & 48.5 & 45.6 & 38.3 \\
\hline & 650 & 195 & 57.8 & 46.6 & 55.8 & 52.7 & 54.4 & 50.7 & 51.3 & 43.8 & 48.6 & 45.6 & 44.9 & 36.5 & 46.7 & 43.1 & 43.0 & 38.0 \\
\hline & 650 & 240 & 58.3 & 51.5 & 56.2 & 50.8 & 55.6 & 50.9 & 53.6 & 41.2 & 50.3 & 46.8 & 47.5 & 35.7 & 45.0 & 41.9 & 40.2 & 37.5 \\
\hline & 650 & 245 & 58.2 & 54.0 & 54.8 & 50.5 & 56.0 & 52.7 & 53.1 & 40.6 & 49.5 & 45.2 & 47.1 & 36.2 & 46.9 & 43.6 & 43.2 & 37.0 \\
\hline & 650 & 250 & 56.5 & 49.8 & 54.3 & 49.3 & 56.7 & 53.4 & 53.6 & 43.3 & 50.0 & 46.6 & 46.8 & 37.4 & 47.6 & 45.3 & 42.4 & 37.7 \\
\hline & 650 & 255 & 57.0 & 48.1 & 546 & 51.7 & 53.3 & 48.8 & 50.8 & 42.0 & 51.0 & 48.2 & 47.5 & 35.3 & 45.3 & 42.9 & 39.7 & 36.9 \\
\hline \multirow[t]{5}{*}{4} & 650 & 280 & 59.7 & 47.3 & 56.4 & 56.5 & 57.1 & 49.8 & 55.7 & 47.4 & 51.9 & 49.2 & 48.0 & 38.2 & 46.9 & 44.0 & 42.0 & 39.3 \\
\hline & 650 & 285 & 60.5 & 47.5 & 57.0 & 57.5 & 57.0 & 50.0 & 55.5 & 46.6 & 52.3 & 49.5 & 48.7 & 39.0 & 47.3 & 44.7 & 41.5 & 39.8 \\
\hline & 650 & 300 & 60.2 & 47.9 & 58.8 & 53.4 & 54.4 & 47.7 & 52.8 & 44.6 & 53.5 & 45.6 & 52.6 & 37.7 & 49.0 & 42.4 & 47.2 & 40.1 \\
\hline & 650 & 300 & 59.8 & 45.8 & 587 & 52.4 & 519 & 462 & 49.0 & 45.2 & 51.3 & 44.7 & 49.9 & 38.5 & 48.4 & 40.6 & 46.1 & 42.5 \\
\hline & 650 & 300 & 59.1 & 48.1 & 57.5 & 52.6 & 52.5 & 45.9 & 50.5 & 44.1 & 51.1 & 44.2 & 49.9 & 37.8 & 47.8 & 40.1 & 46.1 & 39.5 \\
\hline
\end{tabular}
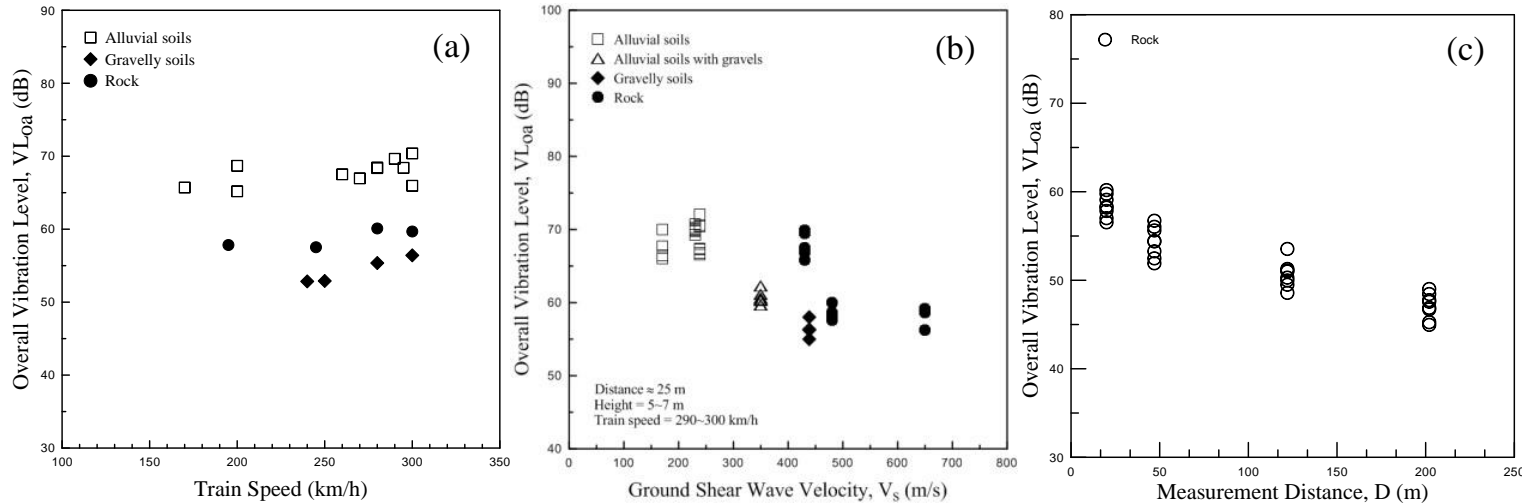

Figure 5. Relationships of $\mathrm{VL}_{\mathrm{oa}}$ and (a) train speed, (b) ground shear wave velocity, (c) attenuation distance.

adopted in this research to predict the level at which high-speed trains induce vibration based on the database of measurement results in Section 3.

\subsection{SVM Prediction Method}

The proposed prediction method in this research is mainly based on the SVM technique, a widely used machine learning tool for re-confirmation. Machine learning is a subfield of applied statistics, which trains on a collected sample dataset and generalizes rules from previous experiences for later classifier applications. The training data with unknown probability distribution are usually applied to extract some general principles and distribution for future predictions on the new testing data. Several types of machine learning algorithms can be categorized based on trained inputs or desired outcomes, such as supervised, unsupervised, semisupervised, and reinforcement learning mechanisms. Recently, the SVM kernel method, a supervised learning model, has become one of the most popular classification algorithms by training known features.

To construct such a classification model, both positive and negative data classes should be provided as training examples in advance, and a trained SVM model 
is then constructed according to the selected features. In the feature space, all learning objects are divided by a hyper plane with a separable margin as wide as possible. The query objects are mapped into the same feature space and assigned to one of the two defined categories based on the locations of the testing object.

This study adopted an SVM classification tool (LIBSVM), which was developed by Lin [7, 8], to predict train-induced vibration levels. All measurement data with defined features were trained, and an SVM model was constructed to predict vibration levels. The selection of classification features, evaluation of different kernel transformation techniques, and prediction results on benchmark datasets are shown and discussed in detail in the following sections.

\subsection{Prediction Process}

In this research, ground shear wave velocity $\left(\mathrm{V}_{\mathrm{s}}\right)$, train speed, and distance from track center (D) are defined as the features in the SVM model. The radial basis function is selected as the kernel type, and the function of multi-class classification is employed in this SVM system. Based on the measured results of possible minimum and maximum vibration levels, the output of the SVM model is classified as four groups of ground vibration levels, as shown in Table 3. The ground vibration levels for Group 1-4 are 30-40 dB, 40-50 dB, 50-60 dB, and 60-70 dB, respectively.

Table 3. Group of ground vibration level

\begin{tabular}{|l|c|c|c|c|}
\hline Group No. & 1 & 2 & 3 & 4 \\
\hline $\begin{array}{l}\text { vibration } \\
\text { level (dB) }\end{array}$ & $30-40$ & $40-50$ & $50-60$ & $60-70$ \\
\hline
\end{tabular}

The training and prediction processes are shown in Figure 6 . In the training state, the system reads the input data at the beginning. It then extracts and normalizes the data to the region $(0,1)$. After transforming the data to the normal form, the system inputs the data to the LIBSVM and begins the training process. The system used the n-fold cross validation, which chooses one fold as the prediction fold. Another fold is used as the training fold for building the hyper plane that is used for prediction. If the prediction results are better than before, the parameter is changed. This process is repeated several times until the system finds that the result is in the local maximum. After the training process, the system uses the hyper plane to predict and classify the vibration level.

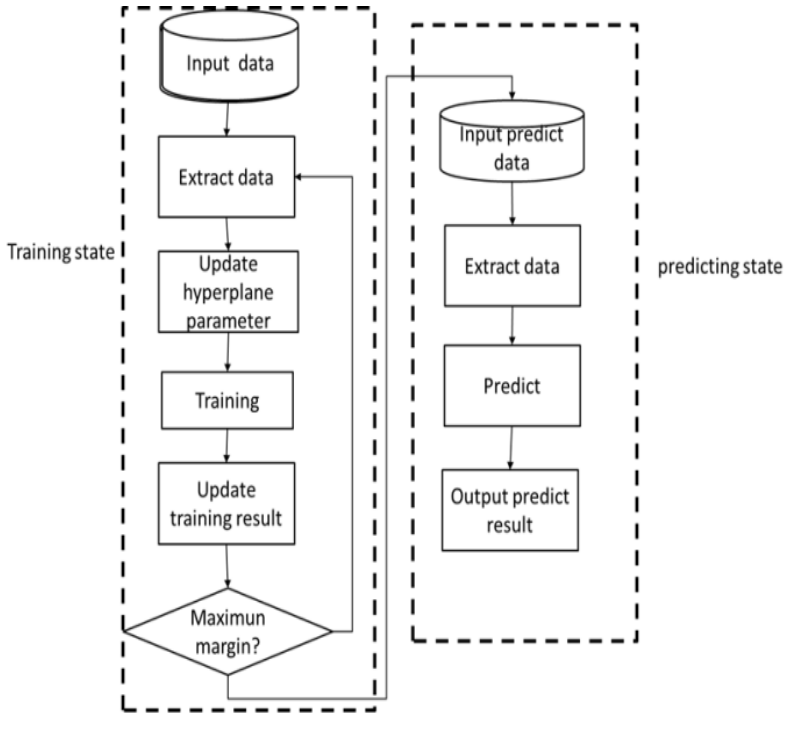

Figure 6. SVM prediction process

\subsection{Prediction Results}

Table 4 presents the prediction results of ground vibration levels using the aforementioned prediction process. The analysis results show that the developed SVM model can predict vibration levels with an accuracy rate of $70 \%-85 \%$ for four types of vibration levels, namely, overall, low, middle, and high frequency ranges. The accuracy rate is defined as the number of correct classification divided by the whole test sets.

Table 4. Prediction results of vibration level

\begin{tabular}{|l|c|c|c|c|}
\hline $\begin{array}{l}\text { Type of } \\
\text { vibration } \\
\text { level }\end{array}$ & low & middle & high & overall \\
\hline $\begin{array}{l}\text { accuracy } \\
\text { rate }\end{array}$ & 0.84 & 0.72 & 0.78 & 0.75 \\
\hline
\end{tabular}

\section{Automatic Prediction System}

The methodology for developing an automatic prediction system for high-speed train-induced vibration levels is also proposed in this study. This automatic prediction system provides a relatively simple method for developing vibration level estimates of high-speed train-induced vibration that can be compared with the acceptability criteria given in Section 5.1. This proposed system can help engineers determine whether vibrationsensitive land uses are close enough to the proposed HSR system, as well as the impact from ground-borne vibration. An example is provided to demonstrate this automatic prediction system. 


\subsection{Vibration Impact Criteria}

The vibration impact criteria in this system cover the human response to building vibration, as well as the building that houses vibration-sensitive instruments and tools. They are briefly introduced in the following sections.

\subsubsection{Vibration Criteria for High-speed Ground Transportation (U.S.A.)}

The vibration criteria for high-speed ground transportation [2] are presented in Table 5. The criteria are based on the maximum levels for a single event. The criteria account for the variation in land use and frequency of events. Table 5 shows that land use is classified into three categories: building, residence, and institution. The frequency of an event is defined as more or fewer than 70 vibration events per day.

Table 5. Ground-borne vibration impact criteria [2]

\begin{tabular}{|l|l|l|}
\hline \multicolumn{1}{|c|}{ Land Use Category } & \multicolumn{2}{|c|}{$\begin{array}{l}\text { Ground-Borne Vibration Impact Le } \\
\text { (VdB re l micro inch/sec) }\end{array}$} \\
\cline { 2 - 3 } & Frequent Events & Infrequent Events \\
\hline $\begin{array}{l}\text { Category l: Buildings where vibration would } \\
\text { interfere with interior operations }\end{array}$ & $65 \mathrm{VdB}^{3}$ & $65 \mathrm{VdB}^{3}$ \\
\hline $\begin{array}{l}\text { Category 2: Residences and Buildings } \\
\text { where people normally sleep. }\end{array}$ & $72 \mathrm{VdB}$ & $80 \mathrm{VdB}$ \\
\hline $\begin{array}{l}\text { Category 3: Institutional land uses with primary } \\
\text { daytime use. }\end{array}$ & $75 \mathrm{VdB}$ & $83 \mathrm{VdB}$ \\
\hline $\begin{array}{l}\text { Notes: } \\
\text { 1. Frequent Events is defined as more than } 70 \text { vibration events per day. } \\
\text { 2. Infrequent Events is defined as fewer than } 70 \text { vibration events per day. } \\
\text { 3. This criterion limit is based on levels that are acceptable for most moderately } \\
\text { sensitive equipment such as optical microscopes. Vibration-sensitive manufacturing } \\
\text { or research will requires special design of HVAC systems and stiffened floors. }\end{array}$ \\
\hline
\end{tabular}

\subsubsection{Generic Vibration for Vibration-Sensitive Equipment}

The Vibration criterion curves are commonly used in the design of facilities that house vibration-sensitive instruments and tools [13]. Vibration criterion curves from a set of one-third octave band velocity spectra have been labeled VC-A to VC-E. The criteria apply to people and vibration-sensitive equipment, as described in Table 6. The criteria for vibration-sensitive equipment are more restrictive than those for human responses, as observed from Table 6. A detailed review is needed for situations involving buildings with high sensitivity equipment near a railway.

\subsection{Automatic Prediction Methodology}

The vibration levels at specific buildings are estimated by reading output values from the proposed prediction system. They are also estimated to account for factors, such as ground shear wave velocity, train
Table 6. Application and interpretation of the generic vibration criterion (VC) curves. [13]

\begin{tabular}{|c|c|c|c|}
\hline $\begin{array}{r}\text { Criterion Curve } \\
\text { (see Figure 1) }\end{array}$ & $\begin{array}{c}\text { Max Level }(1) \\
\text { micrometers/ } \\
\text { sec,rms }\end{array}$ & $\begin{array}{c}\text { Detail Size (2) } \\
\text { microns }\end{array}$ & Description of Use \\
\hline $\begin{array}{l}\text { Workshop } \\
\text { (ISO) }\end{array}$ & 800 & $\mathrm{~N} / \mathrm{A}$ & $\begin{array}{l}\text { Distinctly feelable vibration. Appropriate to } \\
\text { workshops and nonsensitive areas. }\end{array}$ \\
\hline $\begin{array}{l}\text { Office } \\
\text { (ISO) }\end{array}$ & 400 & $\mathrm{~N} / \mathrm{A}$ & $\begin{array}{l}\text { Feelable vibration. Appropriate to offices and } \\
\text { nonsensitive areas. }\end{array}$ \\
\hline $\begin{array}{l}\text { Residential Day } \\
\text { (ISO) }\end{array}$ & 200 & 75 & $\begin{array}{l}\text { Barely feelable vibration. Appropriate to sleep } \\
\text { areas in most instances. Probably adequate for } \\
\text { computer equipment, probe test equipment and } \\
\text { low-power (to } 20 \mathrm{X} \text { ) microscopes. }\end{array}$ \\
\hline $\begin{array}{l}\text { Op. Theatre } \\
\text { (ISO) }\end{array}$ & 100 & 25 & $\begin{array}{l}\text { Vibration not feelable. Suitable for sensitive } \\
\text { sleep areas. } \\
\text { Suitable in most instances for microscopes to } \\
100 \mathrm{X} \text { and for other equipment of low sensitivity. }\end{array}$ \\
\hline VC-A & 50 & 8 & \begin{tabular}{|l|} 
Adequate in most instances for optical \\
microscopes to $400 \mathrm{X}$ microbalances, optical \\
balances, proximity and projection aligners, etc.
\end{tabular} \\
\hline VC-B & 25 & 3 & $\begin{array}{l}\text { An appropriate standard for optical microscopes } \\
\text { to } 1000 \mathrm{X} \text {, inspection and lithography equipment } \\
\text { (including steppers) } \\
\text { to } 3 \text { micron line widths. }\end{array}$ \\
\hline VC-C & 12.5 & 1 & $\begin{array}{l}\text { A good standard for most lithography and } \\
\text { inspection equipment to } 1 \text { micron detail size. }\end{array}$ \\
\hline VC-D & 6 & 0.3 & $\begin{array}{l}\text { Suitable in most instances for the most } \\
\text { demanding equipment including electron } \\
\text { microscopes (TEMs and SEMs) and E-Beam } \\
\text { systems, operating to the limits of their } \\
\text { capability. }\end{array}$ \\
\hline VC-E & 3 & 0.1 & $\begin{array}{l}\text { A difficult criterion to achieve in most instances. } \\
\text { Assumed to be adequate for the most demanding } \\
\text { of sensitive systems including long path, laser- } \\
\text { based, small target systems and other systems } \\
\text { requining extraordinary dynamic stability. }\end{array}$ \\
\hline
\end{tabular}

speed, and distance from the track center. Users must input the position of the alignment for high-speed rail, train speed, and ground shear wave velocity along the high-speed line. The system calculates its distance from the HSR and computes the predicted vibration level automatically.

\subsection{Example of Automatic Prediction System}

Example output results of the proposed automatic prediction system are shown in Figure 7. The vibration levels along the HSR corridor are shown in different colors for each group of vibration levels. In Figure 7, the black region expresses the alignment of the HSR. The red, yellow, blue, and green regions represent vibration levels $4,3,2$, and 1 , respectively. The ground vibration level gradually decreases from 4 to 1 .

The engineer can check the vibration criteria in Section 5.1 based on land use, and determine whether the vibration level induced by HSR exceeds the vibration criteria. If the vibration levels in some regions exceed the vibration criteria, a more detailed assessment is needed when potential problems exist. A detailed analysis is then undertaken during the final design stage to accurately define the level of impact and design mitigation measures. However, detailed analysis is not usually required if the mitigation measure consists of relocating the alignment of HSR systems. 


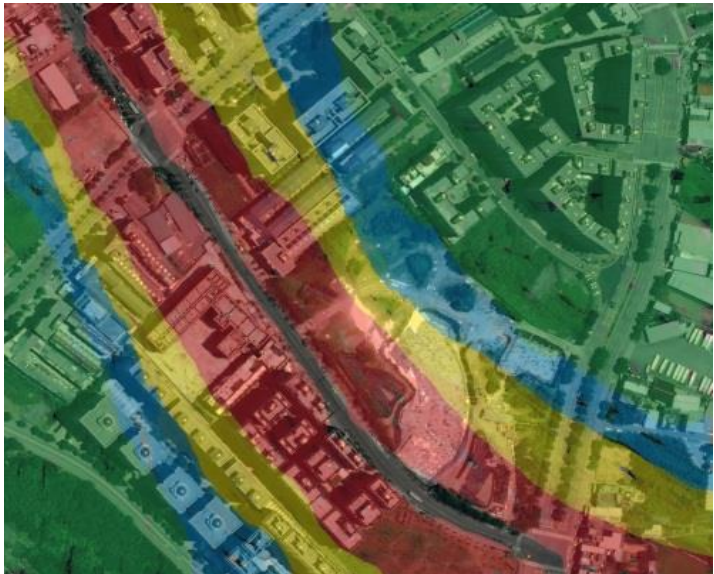

Figure 7. Expected result

\section{Conclusions}

The measurement scheme and analysis methods of ground vibration induced by trains passing on an embankment structure have been presented. The related issues for ground vibration measurements have also been discussed. Based on a wide variety of field measurements and monitoring with vibration sensors, the main characteristics that affect the overall vibration level include train speed, ground condition, measurement distance, and supported structure.

The analysis results show that the developed SVM model can predict vibration levels with an accuracy rate of $70 \%-85 \%$ for four types of vibration levels: overall, low, middle, and high frequency ranges.

The methodology for developing an automatic prediction system for vibration levels induced by highspeed trains has been proposed in this study. An example has also been provided to demonstrate this automatic prediction system. The computer implementation for this proposed system will be developed as future work.

Since the proposed prediction model is based on field measurement results, more field measurement data should be obtained to improve the accuracy of this automatic system. The proposed automatic prediction model can help engineers improve the accuracy of preliminary analysis, and be applied to a large number of assessments.

\section{Acknowledgment}

This study was supported by the National Science Council, Taiwan, under contract number NSC 1002221-E-033-073-MY3.

\section{References}

[1] Chen, Y.J., Shen, Y.J., Chen, K.Y. and Chang, S.M. Some characteristics of ground vibration as induced by high-speed trains, Proceedings of 4th Geotechnical Earthquake Engineering and Soil Dynamics, GSP 181, ASCE, 2008.

[2] U.S. Department of Transportation, Federal Railroad Administration, High-Speed Ground Transportation Noise and Vibration Impact Assessment, Report Number 293630-1, 1998.

[3] U.S. Department of Transportation, Federal Transit Administration, Office of Planning and Environment, Transit Noise and Vibration Impact Assessment, Report Number FTA-VA-90-1003-06, 2006.

[4] Chen Y.J., Ju S.H., Ni S.H. and Shen Y.J. Prediction methodology for ground vibration induced by passing trains on bridge structures. Journal of Sound and Vibration, 302(4-5): 806$820,2007$.

[5] Chen Y.J., Chang S.M. and Han C.K. Evaluation of ground vibration induced by high-speed trains on embankments. Noise Control Engineering Journal, 58(1): 43-53, 2010.

[6] Yoshioka O. Basic characteristics of Shinkanseninduced ground vibration and its reduction measures. Proceeding of international workshop wave 2000, 219-237, Bochum, 2000.

[7] Chang C.C. and Lin C.J. A library for support vector machines, ACM Transactions on Intelligent Systems and Technology, 2(3), Article No. 27, 2011.

[8] L'eon B. and Lin C.J. Support Vector Machine Solvers. On-line: http://www.csie.ntu.edu.tw/ cjlin /papers/bottou_lin.pdf, Accessed: 20/10/ 2013.

[9] Chen, Y.J., Shen, Y.J. and Chen, K.Y. The characteristics and measurement scheme for ground vibration induced by passing train in bridge structures, Inter-Noise2006, 6: 4110-4119, 2006.

[10] Chen Y.J., Huang T.C. and Shen Y.J. Evaluation of ground vibration induced by rail systems, Noise Control Engineering Journal, 61(2): 145-158, 2013.

[11] Chen Y.J., Chiu T.J. and Chen K.Y. Evaluation of ground vibration induced by high-speed trains on bridge structures, Noise Control Engineering Journal, 59(4): 372-382, 2011.

[12] American National Standards Institute, Preferred frequencies and band numbers for acoustical measurement, ANSI S 1.6, 1984.

[13] Gordon C.G. Generic vibration criteria for vibration-sensitive equipment, IEST, 1999. 